receitas publicitárias. Muitas vêem-se e passam a ser vistas, essencialmente, como um negócio. Se esta mudança podia/ pode ser vista como sinal claro de integração na sociedade dominante, não deixa de mostrar que pelo menos uma parte da imprensa gay e lésbica deixou de caber na definição de imprensa alternativa - pela timidez da linguagem, dos conteúdos e das imagens, mas sobretudo pelo abandono do envolvimento político e da luta pela mudança social.

Um tema percorre todos os capítulos da obra: o contributo fundamental da imprensa gay e lésbica para a formação e consolidação da comunidade e da subcultura gay e lésbica norte-americana. Como qualquer imprensa alternativa, também a imprensa gay e lésbica nasceu do silêncio forçado, da necessidade de expressão de visões alternativas do mundo e de denúncia da discriminação; teve uma função fundamental de identificação de interesses comuns, de partilha e de consciencialização; promoveu a criação de redes e organizações de apoio, de entreajuda e de investigação; adoptou o envolvimento político por contraponto à "objectividade" jornalística. Por tudo isso, como refere o autor, quando, face às suas novas tendências, nos interrogamos sobre até que ponto ela ajudará a atingir, um dia, a liberdade plena a resposta só pode ser "muito".

\title{
Mary Talbot (2007) MEDIA DisCOURSE. REPRESENTATION AND INTERACTION, Edinburgh: Edinburgh University Press, ix, +198 pp.
}

\section{Zara Pinto-Coelho}

Centro de Estudos de Comunicação e Sociedade, Universidade do Minho, zara@ics.uminho.pt

Mary Talbot, ex-professora na Universidade de Sunderland, escritora independente e consultora desde 2009, reúne na sua vasta obra uma série de livros onde explora as relações entre a linguagem e o poder social, nos contextos dos média e da cultura de consumo, sendo particularmente reconhecido o trabalho que desenvolveu sobre linguagem e género (Language and Gender, $2^{\mathrm{a}}$ ed. Polity 2010). Podemos dizer que nesta publicação de 2007 a autora se mantém fiel a estes interesses, e propõe que nos centremos na dimensão interaccional do discurso dos média, um assunto ainda muito pouco explorado nos estudos dos média e nos estudos culturais, habitualmente focados na questão da representação (e da ideologia). Para esse efeito, usa um leque de conceitos que vai buscar sobretudo aos estudos culturais (Stuart Hall, 1997), à antropologia dos média (Spitulnik, 2000) e à análise crítica do discurso (Fairclough 1995). Tal significa que a ênfase no discurso-como-interacção não implica o abandono da inscrição do discurso dos média nas práticas sociais e em processos sociais e culturais, como acontece, por exemplo, nos estudos do discurso dos média feitos à luz da análise conversacional.

Talbot explora em grande detalhe três espaços de interacção envolvidos no discurso dos media - as interacções nas comunidades de produção; as interacções nas comunidades da audiência e a interactividade entre produtores e audiências, acrescentando a isto um interesse pelo que chama de interaç̧ão simulada, conceito a partir do qual distingue a interacção entre os média e a audiência da interacção "real", "face-a-face". Para o fazer faz-se acompanhar, em todos os capítulos, de exemplos da Rádio e da TV, que abrangem géneros de entretenimento, de informação e géneros híbridos, e estabelece paralelismos sempre que possível com textos publicados 
nos médias impressos. Fazendo jus ao seu enfoque na interacção, a autora ilustra os argumentos fazendo uma análise detalhada dos casos escolhidos, e motiva os leitores a construírem o seu caminho ao introduzir, no final de todos os capítulos, uma secção de "actividades" e outra de "aprofundamento de leitura".

O livro é composto de oito capítulos, e está dividido em duas partes. Na primeira parte, a autora aborda assuntos que considera centrais na análise do discurso dos média, para na segunda explorar os temas da representação e da interacção, sendo que a leitura da primeira parte é fundamental para compreender os estudos de caso integrados na segunda.

O capítulo 1 é um capítulo crucial da obra. Nele Talbot desenvolve os traços que definem a forma como aborda o discurso dos média à luz, indo beber sobretudo (mas não apenas) à análise crítica do discurso, e mostra a relevância social e cultural do estudo deste tipo de discurso, apoiando-se nas ideias de circuito cultural de Stuart Hall (1997) e de circulação social do discurso na comunidade da antropologia linguística (Spitulnik, 1997). Defende que para analisar o discurso dos média é preciso olhar para os textos, o "tecido em que o discurso se manifesta" (pp. 9). Inspirada em Fairclough (1995), a autora afirma que a análise textual centrada apenas no conteúdo do discurso dos média está inevitavelmente empobrecida porque os conteúdos são sempre concretizados em formas. Importa, portanto, olhar para o modo como a linguagem é usada no discurso, o que é dito e como é dito, mas fazêlo num quadro que implica colocar o texto no centro do olhar, mas sem esquecer a sua inserção na prática discursiva e na prática social.

No capítulo 2, intitulado "reconfigurações", movimentos que caracterizam o mundo moderno, Talbot começa com uma discussão sobre a compressão do tempo e do espaço nos médias modernos, para em seguida explorar duas tensões bastantes familiares nos estudos dos média, a saber, público e privado e informalização e infotainment. Conclui chamando a atenção para outros géneros mediáticos híbridos, incluindo o pastiche e a paródia. Retorna à noção de circuito cultural e à análise crítica do discurso no capítulo 3 para discutir o significado potencial dos textos e o papel activo dos visionadores na produção dos significados, e para sublinhar a cumplicidade activa dos leitores na produção do significado. A desigualdade de poder que caracteriza a relação entre produtores e audiências é um traço que merece destaque, bem como o papel central do leitor implícito como porta de entrada para a ideologia na interpretação. Ilustra esta posição com dois estudos sobre a masculinidade: um a propósito da construção da masculinidade heterossexual em jornais tablóides ingleses, e outro de revistas para homens que incluem novas formas de masculinidade, onde retoma a ideia de fraternidade falaciosa do seu livro de 1995 e defende que a durabilidade da masculinidade clássica hegemónica reside precisamente na sua própria flexibilidade. Em diálogo com os chamados "estudos da audiência", argumenta que isolar o texto ou a audiência como objecto de estudo numa análise do discurso dos média não ajuda, importando sim que o enfoque seja colocado nos dois, e aponta algumas tentativas realizadas nesse sentido.

No capítulo quatro, explora o discurso dos média usando os conceitos de dialogismo e de intertextualidade, que significa conceber o texto mediático como um tecido de vozes e traços de outros textos. Evoca o círculo de Bakhtin, o contributo do mesmo para uma visão interactiva, recíproca e social da linguagem e para a ultrapassagem do modelo da comunicação como transmissão, e Julia Kristeva a propósito da intertextualidade, para sublinhar o envolvimento dos leitores no diálogo intertextual e assim na construção da coerência dos textos. Escolhe para 
mostrar a natureza dialógica e intertextual do discurso dos média três questões: a neutralidade do jornalismo radiofónico, estabelecendo paralelismos entre Bakhtin e Goffman na sua atenção ao posicionamento e à interacção; assuntos relacionados com a atribuição, em editoriais da imprensa escrita, e com a aparente oposição entre dialogismo e autoritarismo em documentários televisivos.

Na segunda parte da obra, a autora explora os três espaços de interacção que o discurso dos média envolve, desenvolvendo assim os temas apresentados na primeira parte. No capítulo 5 , regressa à discussão sobre a interacção simulada, para analisar de forma mais aprofundada tentativas de ultrapassagem do fosso entre produtores e audiências e a difusão da conversação informal (chat) como género televisivo e radiofónico. Partindo de uma característica chave do discurso televisivo e radiofónico, o ethos comunicativo, salientada por autores como Scannell, a autora defende, ao contrário deste mesmo autor, que a sociabilidade promovida pelos media tem também um lado negativo, o de precisar de apagar a diferença social. Com Morley (2000) insiste que os estudos dos média devem reconhecer a presença destas duas forças na vida contemporânea. Associado ao conceito de socialidade está o de personalidade sintética, que a autora considera confuso, usando em sua substituição o de personalização sintética, presente no trabalho de Fairclough, juntando assim preocupações de poder à discussão sobre a socialidade e a informalização nas relações entre produtores e audiências. Incidindo sobre a ideia dos textos radiofónicos e televisivos como espectáculo, onde se oferecem relações e identidades sociais, explora no capítulo 6 os significados interpessoais, continuando, de alguma maneira a discussão iniciada no capítulo anterior. Talbot põe em realce a televisão de estilo de vida consumista, e a tensão entre tendências que envolvem estratégias de equalização do poder, autenticidade e sinceridade, e os seus opostos, quando se impõem hierarquias baseadas na perícia, na performatividade e na diversão, como é o caso de programas de estilos de vida dominados pelo discurso da celebridade, como o do Olivier na cozinha. As representações das identidades e relações discutidas neste capítulo projectam valores culturais de consumismo, o individualismo da celebridade e o prestígio das normas interacccionais que são vistas como sendo masculinas.

O capítulo sete constitui o momento em que a atenção da autora vira dos textos para os quadros interactivos da produção e recepção (Thompson, 1995), mostrando a complexidade do palco e dos bastidores (Goffman, 1969) das comunidades engajadas na produção de textos mediáticos e na sua audiência. Usa para esse efeito vários exemplos de estudos de natureza etnográfica (e.g. Born, 2002) e dos chamados estudos de audiência, dando também destaque à linha antropológica (Spitulnik, 1997) mas sem deixar de usar exemplos de programas ou textos impressos. O livro culmina com Talbot focada na interactividade entre produtores e audiências, das formas mais convencionais às novidades possibilitadas pelas novas tecnologias de cabo, satélite e internet. Em debate não está o aumento de conteúdos e do acesso aos mesmos, mas a interacção social ente membros das comunidades que compõem a audiência e membros das comunidades de produção, a interacção real e a retórica. O dialogismo entre uns e outros nunca foi tão grande, as fronteiras que os separam estão a esbater-se de alguma forma, surgindo necessariamente a questão do controlo ou de falta dele. Talbot encerra afirmando que o controlo corporativo crescente da internet e a liderança tecnológica e económica da indústria das telecomunicações no processo de desenvolvimento resultarão, no futuro, em audiências sujeitas à posição de consumidor (pp.173). 